\title{
O Agente Comunitário de Saúde e a consolidação do Sistema Único de Saúde: reflexões contemporâneas
}

\section{$1{ }^{1}$ Karine de Oliveira Gomes, ${ }^{2}$ Rosângela Minardi Mitre Cotta, ${ }^{3}$ Sandra Minardi Mitre, ${ }^{4}$ Rodrigo Siqueira Batista, ${ }^{5}$ Mariângela Leal Cherchiglia I}

Resumo: Os agentes comunitários de saúde (ACS) são personagens-chave na implantação de políticas voltadas para a reorientação do modelo de saúde, tendo como base a atenção primária. Este estudo apresenta uma revisão de literatura, dirigida à análise crítica sobre a contribuição deste profissional para a consolidação do Sistema Único de Saúde (SUS). Considerando que as concepções acerca do processo saúde-doença dão sentido à prática sanitária e às ações dos profissionais de saúde, inicialmente discutiu-se a evolução dos paradigmas sanitários e a influência das correntes de pensamentos neste processo, apresentando as principais diferenças entre o paradigma flexneriano e o paradigma da produção social da saúde. Neste contexto, o SUS desponta como um novo sistema de saúde, com princípios e diretrizes que configuram o Programa Saúde da Família como estratégia revolucionária, por apresentar respostas aos problemas não solucionados pelo sistema sanitário hegemônico, baseado no paradigma até então dominante. Assim, por colocar em foco o cuidado, a atenção primária, a prática sanitária da vigilância à saúde e o trabalho em equipe multiprofissional, a formação dos profissionais para a abordagem do processo saúde-doença com enfoque em saúde da família surge como desafio para o êxito do modelo sanitário proposto. Destarte, a reflexão crítica sobre a função do ACS aponta para conflitos entre pressupostos teóricos do modelo e a prática deste profissional, destacando a necessidade de capacitação permanente, críticoreflexiva e baseada em metodologias problematizadoras, como estratégia de potencialização para a efetiva mudança do modelo de saúde, no contexto da práxis do PSF.

> Palavras-chave: Agente Comunitário de Saúde; Sistema Único de Saúde; Programa Saúde da Família; Formação Profissional; Problematização.

\author{
1 Doutoranda em Saúde Pública \\ pelo Departamento de Medicina \\ Preventiva da Universidade \\ Federal de Minas Gerais (UFMG). \\ Professora Assistente I do \\ Instituto Multidisciplinar em \\ Saúde, Campus Anísio Teixeira, \\ Universidade Federal da Bahia \\ (UFBA). Endereço eletrônico: \\ kogomes@yahoo.com.br \\ 2 Doutora em Saúde Pública \\ pela Universidade de Valência, \\ Espanha. Professora Associada \\ do Departamento de Nutrição \\ e Saúde, Universidade Federal \\ de Viçosa (UFV). Tutora e \\ Orientadora de Aprendizagem do \\ Curso de Ativação de Processos \\ de Mudanças na Formação \\ Superior de Profissionais de \\ Saúde pelo Ministério da \\ Saúde/Fiocruz/Rede Unida. \\ Coordenadora do Programa \\ de Inovação em Docência \\ Universitária da UFV. Endereço \\ eletrônico: rmmitre@ufv.b \\ ${ }^{3}$ Professora Assistente da \\ Faculdade de Ciências Médicas \\ de Minas Gerais. Mestranda em \\ Saúde Pública no Departamento \\ de Medicina Preventiva (UFMG); \\ Especialista em Ativação \\ de Processos de Mudanças \\ na Formação Superior de \\ Profissionais de Saúde. Endereço \\ eletrônico: sanmitre@terra.com.br \\ ${ }^{4}$ Doutor em Ciências. Professor \\ Adjunto do Departamento \\ de Nutrição e Saúde, \\ Universidade Federal de Viçosa \\ (UFV). Endereço eletrônico: \\ rsiqueirabatista@terra.com.br \\ ${ }^{5}$ Doutora em Saúde Pública. \\ Professora Adjunta do \\ Departamento de Medicina \\ Preventiva e Social, Universidade \\ Federal de Minas Gerais (UFMG) \\ Endereço eletrônico: cherchml@ \\ medicina.ufmg.br
}


Os agentes comunitários de saúde (ACS) têm sido considerados membros efetivos do trabalho no Sistema Único de Saúde (SUS), e não apenas meros suportes para a execução de determinadas ações em saúde, representando personagens-chave na implantação de políticas voltadas para a reorientação do modelo de assistência em saúde (SILVA; DALMASO, 2002; DAL POZ, 2002).

Historicamente, o modelo de atenção à saúde no Brasil tem sido marcado pela predominância da assistência médica curativa e individual e pelo entendimento de saúde como ausência de doença, princípios definidores do modelo flexneriano. $\mathrm{O}$ rompimento deste paradigma veio com o ordenamento jurídico-institucional de criação e implantação do SUS, uma vez que o modelo anterior não respondia aos problemas da organização das ações e serviços de saúde de maneira a atender às reais necessidades da população (BYDLOWSKI et al., 2004; SCHERER et al., 2005).

Fruto da luta do Movimento da Reforma Sanitária Brasileira, a criação e implementação do SUS foram marcadas pelo paradigma da produção social da saúde, caracterizado por uma nova e ampliada concepção do processo saúdedoença e pela prática sanitária pautada na vigilância da saúde como resposta social organizada aos problemas de saúde, em todas as suas dimensôes, mediante operações intersetoriais articuladas por diferentes estratégias de intervenção (SANTOS; WESTPHAL, 1999; MENDES, 2006).

Neste sentido, o Programa Saúde da Família (PSF) surgiu no cenário brasileiro como estratégia de reorientação do modelo assistencial, substituindo o modelo tradicional por um cujas principais características são o enfoque sobre a família, a partir de seu ambiente físico e social como unidade de ação; adscrição da clientela através da definição de território de abrangência; estruturação de equipe multiprofissional; ação preventiva em saúde; detecção das necessidades da população no lugar da ênfase na demanda espontânea e a atuação intersetorial com vistas à promoção da saúde (BRASIL, 2001; BORNSTEIN; STOTZ, 2008).

Considerando que o PSF tem, entre suas características mais marcantes, a inclusão do ACS na equipe de saúde como um mediador entre a população e o serviço de saúde, por meio de açôes educativas, prevenção de agravos e de promoção e vigilância da saúde e como agente social, no sentido de organização da comunidade e de transformação de suas condições, este artigo ${ }^{1}$ tem como 
objetivo realizar uma analise crítica sobre a implicação deste profissional na implementação e consolidação do SUS, no contexto das concepções que norteiam suas açōes e sua formação profissional.

\section{Metodologia}

O presente estudo ${ }^{2}$ consiste em uma revisão de literatura e realiza uma análise crítica sobre a contribuição do ACS na implementação e consolidação do SUS. Adotou-se como ponto de partida uma análise sobre a evolução dos paradigmas sanitários, seguida da discussão sobre a função e a prática do ACS neste contexto, finalizando com uma reflexão sobre a necessidade de capacitação permanente deste profissional como estratégia de potencialização para a efetiva mudança do modelo de saúde.

Foram buscados os trabalhos publicados nos últimos 12 anos, considerando que foi a partir da Norma Operacional Básica do Sistema Único de Saúde de 1996 (NOB SUS No1/96) que o PSF ganhou mais impulso para sua implantação, e o período de coleta de dados ocorreu entre agosto de 2007 e junho de 2008.

\section{Paradigmas sanitários e correntes de pensamento: da concepção à ação}

Mudanças de paradigmas estão ocorrendo, tanto no âmbito da ciência como da arena social. O paradigma que agora se questiona dominou as diferentes culturas por várias centenas de anos com suas idéias e valores entrincheirados, caracterizados pela visão do universo como um sistema mecânico composto de blocos elementares; do corpo humano como uma máquina e da vida em sociedade como uma luta competitiva pela existência (CAPRA, 2006).

A necessidade de novos olhares sobre a realidade vem afirmar que o paradigma da decifração, manipulação e controle dos fenômenos começa a ser questionado pela própria ciência, devido, em grande parte, à descoberta dos fenômenos complexos, que são difusos, ambíguos e ambivalentes. Desta forma, a complexidade da realidade exige o avanço no sentido de compreender formas de agir que possam novamente religar os conhecimentos, o contexto e a singularidade das interaçōes, assim como ampliar a compreensão dos fenômenos (FALCÓN et al., 2006).

Do mesmo modo, o sistema de saúde brasileiro vive há mais de duas décadas um processo de mudança iniciado com o movimento da reforma sanitária, na 
década de 1980 (CAMPOS, 2003). No entanto, para o entendimento da história e do desenvolvimento das políticas de saúde no país, torna-se fundamental a discussão sobre a evolução dos paradigmas sanitários e a influência das correntes de pensamentos neste processo, uma vez que as concepções acerca do processo saúde-doença dão sentido à prática sanitária e às ações dos profissionais de saúde.

As correntes de pensamento sociológicas são visões de mundo que direcionam a construção do conhecimento da realidade e a interpretação das relaçooes entre medicina, saúde e sociedade (TRIVIÑOS, 1987; RICHARDSON, 1999; MINAYO, 2007). Por conseguinte, as diferentes visões presentes nas interpretações da realidade pelos distintos sujeitos sociais refletem a dificuldade do pensamento em apreender e compreender a "saúde" em toda sua complexidade e articulações (MINAYO, 2007, p. 80).

O paradigma dominante no campo científico da saúde fundamenta-se em uma série de pressupostos oriundos do positivismo (SCHERER et al., 2005, p. 55), sendo o funcionalismo, como classificação do positivismo, a corrente de pensamento mais utilizada nas abordagens e práticas do setor saúde (MINAYO, 2007, p. 91).

Este paradigma, denominado biomédico ou flexneriano, é caracterizado por um conjunto de elementos que coexistem e se complementam, tais como o curativismo, mecanicismo, biologismo, individualismo, especialização e tecnificação (SANTOS; WESTPHAL, 1999; SCHERER et al., 2005; MENDES, 2006; CAPRA, 2006), fatores que reduzem a atenção sanitária à especialização médica e à medicalização da vida (MARCONDES, 2004; TESSER, 2006; COTTA et al., 2007; BESEN et al., 2007).

Influenciado pela teoria funcionalista, no modelo flexneriano a saúde-doença é entendida como "um estado de perturbação no funcionamento normal do indivíduo humano total, compreendendo-se o estado do organismo como o sistema biológico e seus ajustamentos pessoal e social”, ou seja, a doença representa "uma conduta desviada" e a prática médica é um mecanismo do sistema social que reconduz o doente à normalidade, controlando seus desvios individuais (MINAYO, 2007, p. 93). Assim, o ser humano é visto como uma máquina e a doença como um mau funcionamento do organismo, conferindo ao médico o papel mecanicista de intervir física ou quimicamente para consertar um defeito de funcionamento do mecanismo (SANTOS; WESTPHAL, 1999; SCHERER 
et al., 2005; MENDES, 2006; CAPRA, 2006; TESSER, 2006; DIAS et al., 2007; LEFEVRE; LEFEVRE, 2007; MINAYO, 2007).

Esta concepção não só sustenta a razão de ser do sistema produtivo, através do controle tecnológico da doença que reforça o capitalismo contemporâneo e o livre comércio de bens e serviços ditos de saúde (SANTOS; WESTPHAL, 1999; CAMPOS, 2003; LEFEVRE; LEFEVRE, 2007), como também promove o deslizamento permanente da doença para o doente, levando à individualização da saúde pública e à culpabilização da população diante da falta de autocuidado (MARCONDES, 2004; VASCONCELOS, 2006; LEFEVRE; LEFEVRE, 2007; BESEN et al., 2007; NORONHA et al., 2009).

De mais a mais, o paradigma flexneriano desconsidera a participação dos usuários no seu próprio processo de recuperação e tampouco estimula a participação comunitária para a transformação dos determinantes da saúde (DUARTE et al., 2007), reforçando a dominação corporativa dos médicos em defesa de privilégios e interesses, além de menosprezar o senso comum e a cultura da população (STOTZ; ARAÚJO, 2004; RIOS et al., 2007) e conferir tratamento subalterno aos outros profissionais da área (MINAYO, 2007, p. 95).

Entretanto, a influência da concepção biomédica na saúde tem sido alvo de muitas críticas, sendo responsabilizada pela perda da capacidade de adaptação da população ao meio social, em função da medicalização da vida e da ilusão de que a medicina é capaz de acabar com a dor, com o sofrimento e com a doença, o que compromete a capacidade cultural dos indivíduos e da sociedade contemporânea de lidar com a vida e morte (CAMPOS, 2003; MARCONDES, 2004; MENDES, 2006; MINAYO, 2007; CAMPOS, 2007).

Neste contexto, em oposição ao positivismo e em resposta às insuficiências do paradigma flexneriano, emerge a fenomenologia e suas linhas holísticas que ampliaram a concepção da saúde e da doença. Assim, a saúde passou a ser compreendida como um processo, resgatando a responsabilidade dos indivíduos e introduzindo o componente ético na relação da ciência com a sociedade, o que evidenciou a necessidade da reorientação do sistema de saúde (RICHARDSON, 1999; MINAYO, 2007).

Deste modo, a humanização ${ }^{3}$ da saúde aparece como intervenção, afirmando que as práticas do processo saúde-doença, longe de se reduzirem a uma evidência orgânica e objetiva, estão intimamente relacionadas com as 
características de cada contexto sociocultural e também com a experiência subjetiva de cada pessoa (MARCONDES, 2004; MENDES, 2006; DIAS et al., 2007, NORONHA et al., 2009), passando pela autonomia do sujeito e por sua inter-relação com os demais sujeitos e com o ambiente, em uma intrincada teia de interações (CAPRA, 2001; RÊGO et al., 2007).

Não obstante, foi a corrente de pensamento marxista que determinou o caráter de posição ideológica e política no Brasil, nas décadas de 70 e 80 , repercutindo nos movimentos sociais e influenciando questôes relativas ao direito e outros temas emergentes. No setor saúde, seu peso teórico, político e ideológico, aliado à nova concepção de saúde, foi manifestado na VIII Conferência Nacional de Saúde, em 1986, e posteriormente, no capítulo dos Direitos Sociais da Constituição Cidadã de 1988, com a criação do SUS e a aprovação da universalização da saúde (SANTOS; WESTPHAL, 1999; BUCHABQUI et al., 2006; MINAYO, 2007).

O SUS desponta então como um novo paradigma na atenção à saúde, com princípios e diretrizes que rompem com o modelo flexneriano, criando uma nova forma de produzir e distribuir as ações e serviços de saúde a partir da configuração do PSF como sua dimensão operacional, sintonizado com a universalidade, equidade e integralidade da atenção (SCHERER et al., 2005; MENDES, 2006). Ademais, o PSF coloca em foco o Paradigma da Produção Social da Saúde, com ênfase no cuidado, na atenção primária, na prática sanitária da vigilância à saúde e no trabalho em equipe multiprofissional (SANTOS; WESTPHAL, 1999; SCHERER et al., 2005; MENDES, 2006; NORONHA et al., 2009).

\section{Função e formação do Agente Comunitário de Saúde: conflitos entre teoria e prática}

Hoje o Brasil conta com o trabalho de 243.000 ACS, presentes tanto em comunidades rurais e periferias urbanas quanto em municípios altamente urbanizados e industrializados, cobrindo $62,5 \%$ da população do país. Apesar de ser um número ainda distante do desejado, é expressiva a importância deste profissional para o aumento do acesso aos serviços básicos de saúde, uma vez que a cobertura das Equipes de Saúde da Família (ESF) alcançou apenas 52,4\% da população em 2008 (BRASIL, 2008).

Desde o início, a vida profissional do ACS foi cheia de conflitos e incertezas, uma vez que o Programa de Agentes Comunitários de Saúde (PACS) foi criado 
em 1991 e suas atribuições foram definidas somente em 1997, pela Portaria no. 1.886 (BRASIL, 1997), que aprovou as normas e diretrizes do PACS/PSF. Em seguida, o Decreto no. 3.189/1999 fixou as diretrizes para o exercício da atividade dos ACS (BRASIL, 1999), mas a regulamentação da profissão só aconteceu em 2002, com a promulgação da Lei no. 10.507 (BRASIL, 2002).

Segundo a Política Nacional de Atenção Básica, são atribuições dos ACS promover a integração da equipe de saúde com a população; trabalhar com adscrição das famílias em base geográfica definida; desenvolver açōes educativas com as famílias; realizar e atualizar os cadastros; orientar as famílias quanto à utilização dos serviços de saúde disponíveis; desenvolver atividades de promoção da saúde, prevenção das doenças e agravos e de vigilância à saúde, mantendo a equipe informada sobre as famílias em situação de risco; acompanhar, por meio de visita domiciliar, todas as famílias e indivíduos sob sua responsabilidade e ajudar na prevenção/controle da malária e da dengue (BRASIL, 2006). Desta forma, o ACS pode ser visto como um trabalhador sui generis, uma vez que suas funçôes transcendem o campo da saúde, exigindo-lhes atenção a múltiplos aspectos das condiçôes de vida da população. Além disso, sua identidade comunitária e a importância do seu papel social os diferenciam dos demais trabalhadores da saúde, principalmente ao atuarem como mediadores entre as distintas esferas de organização da vida social, ajudando a abrir as portas da solidariedade comunitária e facilitando o acesso aos direitos sociais (NOGUEIRA et al., 2000).

Assim, é possível identificar duas dimensōes principais na proposta de atuação para o ACS: uma mais estritamente técnica, relacionada ao atendimento aos indivíduos e famílias, à intervenção para prevenção de agravos ou para o monitoramento de grupos ou problemas específicos, e outra mais política, porém não apenas de solidariedade à população e de inserção da saúde no contexto geral de vida, mas também no sentido de organização da comunidade e de transformação destas condições (SILVA; DALMASO, 2002).

Entretanto, o fato de o ACS ser uma pessoa que convive com a realidade e as práticas de saúde da comunidade onde mora e trabalha, associado à sua formação ainda baseada nos referenciais biomédicos, faz deste um ator que veicula as contradições e, ao mesmo tempo, a possibilidade de um diálogo profundo entre esses dois saberes e práticas (NUNES et al., 2002), criando-se, desta forma, um dilema permanente para o ACS, na medida em que a convivência entre estes 
diferentes componentes entra em conflito na dinâmica do cotidiano (SILVA; DALMASO, 2002). Neste sentido, vários estudos têm procurado identificar as funçōes, ações e concepções sobre o cotidiano do trabalho do ACS — incluindo as repercussōes sobre a qualidade de vida (KLUTHCOVSKY et al., 2007) e os resultados demonstram que eles têm encontrado muitas dificuldades para cumprir com suas atribuições, tanto pelo amplo leque de exigências quanto pelas limitadas condiçôes socioeconômicas das famílias acompanhadas.

Para Nunes et al. (2002) o ACS apresenta um caráter híbrido e polifônico que o inscreve de forma privilegiada na dinâmica de implantação e de consolidação do novo modelo de saúde, pois, numa posição estratégica de mediador entre a comunidade e o serviço de saúde, ora ele pode funcionar como facilitador, ora como empecilho neste processo. Contudo, de uma maneira geral o agente é referenciado como o elo entre a equipe de saúde e a comunidade, sendo o principal responsável pela efetivação do vínculo nesta relação (BRASIL, 2001; SILVA; DALMASO, 2002; ROSA et al., 2004; LEVY et al., 2004; ZANCHETTA et al., 2005; BORNSTEIN; STOTZ, 2008).

Em estudo realizado em Bauru, os ACS relataram realizar o cadastramento das famílias, visitas domiciliares, identificação de doenças e encaminhamento à Unidade Básica de Saúde e um trabalho de prevenção a partir da orientação a pacientes diabéticos, hipertensos e gestantes. Além disso, procuravam solucionar os problemas de acordo com as prioridades de cada família, oferecendo esclarecimentos relacionados ao lixo, alimentação, desnutrição e vacinação (LEVY et al., 2004).

Ferraz e Aerts (2005) encontraram semelhanças nas atividades desenvolvidas pelos ACS em Porto Alegre, acrescentando a orientação sobre higiene e uso correto de medicamentos. $\mathrm{O}$ estudo também identificou a realização de atividades administrativas que não estão preconizadas pelo Ministério da Saúde e que descaracterizam o papel do agente, tais como atuar na recepção da unidade de saúde, organizar pastas e prontuários e ainda controlar materiais e almoxarifado.

Este resultado é relevante, pois o tempo gasto na realização destas atividades pode comprometer a qualidade ou até mesmo o cumprimento das atribuiçōes profissionais que lhes são exigidas, além disso, contraria a determinação da Política Nacional de Atenção Básica, que permite ao ACS desenvolver atividades nas unidades básicas de saúde, desde que sejam vinculadas às suas atribuições (BRASIL, 2006). 
Em Sorocaba, as ACS descreveram como suas principais atividades visitar sistematicamente as famílias sob sua responsabilidade; investigar a existência de situações de risco; orientar para a prevenção de doenças e para as necessidades encontradas; levar os problemas para discussão com a equipe e servir à comunidade ensinando o que aprenderam. Embora o enfoque preventivo tenha sido tão enfatizado, o trabalho de orientação foi essencialmente individualizado e centrado na prevenção de riscos específicos (DUARTE et al., 2007), resultado que também foi verificado por Silva e Dalmaso (2002).

Por outro lado, muitas vezes os ACS reproduzem comportamentos calcados em velhas concepções de favores e facilitação dos trâmites burocráticos (PEDROSA; TELES, 2001), colocando em jogo na sua relação com a família e com a equipe não só os procedimentos necessários aos cuidados da saúde, mas também relações de barganha e poder para a geração de privilégios (SILVA; DALMASO, 2002; NUNES et al., 2002), ferindo os princípios do SUS, especialmente a equidade, quando eles favorecem o acesso a pessoas mais próximas ou afins.

Outro paradoxo relacionado à atuação do ACS éo alto grau de intervencionismo na vida das pessoas (CAMPOS, 2007), percebido principalmente quando os critérios de avaliação da saúde ou modo de vida das pessoas da comunidade são exclusivamente guiados pelas recomendações biomédicas, sem esforço de contextualização ou reflexão sobre sua realidade (NUNES et al., 2002).

Silva e Dalmaso (2002), avaliando os ACS do Projeto Qualis/PSF em São Paulo, identificaram como práticas preponderantes as ações em torno da assistência médica e do controle de riscos, tais como reforço da conduta médica, controle de medicação/tratamento, marcação de exames e consultas, ilustrando um dos problemas da visita domiciliar, que, segundo Franco e Merhy (1999), pode significar uma excessiva intromissão na vida das pessoas, limitando, sobremaneira, seu grau de privacidade e liberdade. Esta atitude pode ser justificada pela formação pautada no modelo biomédico e na visão positivista que reduz a doença à falta de cuidados por parte dos indivíduos, oferecendo práticas profissionais baseadas na imposição de conhecimentos técnicos e na desvalorização do saber popular e das condições de vida da população (MARCONDES, 2004; STOTZ; ARAÚJO, 2004; BESEN et al., 2007).

Todavia, no estudo de Zanchetta et al. (2005), a maior preocupação dos ACS foi revelar o compromisso do sistema de saúde com a comunidade, mas, 
percebendo-se impossibilitados de promover a saúde, em função da necessidade de medidas intersetoriais para a reversão da miséria e para o alcance de melhor perspectiva de vida da população, seu trabalho se restringiu ao controle de doenças crônicas e à prevenção de outros agravos através do esclarecimento de dúvidas, criação de vínculos de confiança, reforço à solidariedade e escuta à clientela, visando a intervir em suas vulnerabilidades.

Norteados pelo referencial médico e biológico, os profissionais de saúde sentem-se impotentes diante da miséria, desemprego, falta de higiene, fome. Estes são problemas para os quais não há cura imediata, mas são tão graves que precisam ser cuidados e, neste sentido, ouvir o que a comunidade tem ou precisa dizer é acolher. O acolhimento, então, passa a ser uma forma de cuidar e pode ser o primeiro passo para ampliar um diálogo e gerar possibilidades e oportunidades (DUARTE et al., 2007).

Além disso, quando se estabelece uma ação em saúde como prática de cuidado, cria-se uma parceria entre profissional e indivíduo, buscando as origens e significados do problema e as formas de enfrentá-lo (SILVA; DALMASO, 2002). Assim, através da experiência do extenso abandono social da comunidade, os ACS vivenciaram a ampliação da concepção de saúde e se conscientizaram da necessidade do desenvolvimento de açôes integradas entre o PSF e o governo para complementar as orientações gerais e o acompanhamento pós-consulta (ZANCHETTA et al., 2005), demonstrando uma visão fenomenológica e dialética da realidade.

Entretanto, para o enfrentamento dessas condições adversas, faz-se necessária a identificação e definição não só das necessidades e demandas em saúde, mas também das condiçôes institucionais para viabilização das açôes e dos caminhos a serem percorridos — o que inclui a formação adequada dos profissionais de saúde para atuar no SUS e nos seus diferentes níveis, especialmente na atenção básica, de modo a torná-los capazes de enfrentar os problemas resultantes da pobreza e da desigualdade social tão presentes no cotidiano brasileiro (COTTA et al., 2007).

\section{A capacitação e educação permanente como estratégia de potencialização para a reorientação do modelo de saúde}

Diante de tantos desafios impostos ao trabalho dos ACS, ressalta-se a necessidade de se estabelecer inovaçôes no cuidado em saúde, priorizando-se o vínculo e o acolhimento nas relações. A tudo isso se associa a criatividade exigida para o 
enfrentamento dos obstáculos que são impostos pelas situações de vulnerabilidade, que tanto comprometem a saúde dos indivíduos.

Surge então a necessidade de que os serviços de saúde e seus profissionais sejam mais flexíveis, desvinculados dos procedimentos tradicionais cristalizados no núcleo de suas formações, passando a adotar uma forma de interação inovadora, contextualizada e em consonância com as crenças e valores das famílias no cenário social e político. Neste sentido, a capacitação e educação permanente da equipe multiprofissional tornam-se fundamentais para que os profissionais busquem solucionar o processo saúde-doença no contexto da família, direcionando o olhar e as ações de saúde para além das práticas curativas (NORONHA et al., 2009).

Contudo, a formação pautada no modelo de educação tradicional (flexneriano) dos cursos médicos (PEDROSA; TELES, 2001; ROSA et al., 2004; BUCHABQUI et al., 2006; DUARTE et al., 2007; BESEN et al., 2007) constitui um obstáculo para o pleno desenvolvimento do potencial dos profissionais de saúde, uma vez que se baseia na concepção "bancária" para a qual a educação é o ato de depositar, transferir e transmitir valores e conhecimentos para seres de adaptação e ajustamento, passivos, ingênuos, acríticos e possuidores de um poder criador mínimo (FREIRE, 1987).

As conseqüências desta formação tradicional foram constatadas pelo trabalho de Cotta et al. (2006), que verificaram o inadequado nível de apreensão e conhecimento dos princípios do SUS e do PSF por 40,7\% dos profissionais de saúde entrevistados no município de Teixeiras, Minas Gerais, dentre os quais a maioria era ACS (44,4\%). Destacaram, ainda, a lacuna na formação dos profissionais e demonstraram que a abordagem do processo saúde-doença com enfoque em saúde da família representa um importante desafio para o êxito do modelo sanitário proposto.

Rosa et al. (2004) encontraram resultado semelhante na Bahia. Nesse estudo, apesar de os ACS se identificarem como trabalhadores do SUS, eles desconheciam seus princípios e não conseguiam incorporar o PACS/PSF enquanto programas integrantes deste sistema. Além disso, eles não conseguiam perceber a dimensão do poder de transformação que possuíam enquanto agentes sociais de mudanças, principalmente por apresentarem a percepção da saúde como algo oferecido de forma gratuita e não como um direito universal inscrito na Constituição Federal de 1988. 
Segundo Bordieu (2005), os agentes sociais não agem de maneira disparatada, não fazem coisas sem sentido e não realizam atos gratuitos. Por conseguinte, a palavra gratuito remete, por um lado, à idéia de não-motivado, de arbitrário, um ato do qual não podemos fazer sentido. Por outro, o que é gratuito é o que não é pago, que não custa nada, que não é lucrativo, identificando-se no encaixe destes dois sentidos a busca da razão de ser de uma conduta à sua explicação pela procura de fins econômicos (BOURDIEU, 2005).

Esses resultados demonstram o quanto a capacitação oferecida aos ACS é incompleta e reforçam que humanizar a formação, bem como promover reflexões sobre os princípios do SUS é imprescindível para a adequada compreensão sobre o sistema pelos ACS e a conseqüente implantação satisfatória do mesmo (ROSA et al., 2004). Nessa perspectiva, entre os desafios para as práticas de formação e educação permanente, encontra-se o de produzir uma nova consciência do sujeito público que integre os processos de construção contra-hegemônica e gere um novo pensamento e liderança capazes de propor uma nova maneira de contribuir com a construção da viabilidade de modelos de saúde alternativos (PAIM, 2001). Além disso, com a implantação do PSF, o papel do ACS foi ampliado, exigindo novas competências no campo político e social, principalmente ligadas à promoção da saúde. Entretanto, o processo de qualificação deste profissional ainda é desestruturado, fragmentado, e na maioria das vezes, insuficiente para desenvolver as competências necessárias para o adequado desempenho de seu papel (TOMAZ, 2002).

A inadequação do nível de informação dos profissionais sob as bases nas quais se orienta a Política de Saúde prejudica a adoção de novas práticas na perspectiva de um novo modelo de atenção e gera a necessidade de que se instaure um processo de qualificação, através da oferta de diversos cursos de capacitação (COTTA et al., 2006), elaborados e baseados no desenvolvimento de competências, utilizando métodos de ensino-aprendizagem inovadores, reflexivos, críticos e centrados no educando, cujos objetivos centrais devem ser transformá-los em sujeitos proativos (TOMAZ, 2002; MITRE et al., 2008; DUARTE et al., 2007).

Assim, se os agentes são considerados como organizadores do acesso (cadastrador e orientador do uso dos serviços), "olheiros" da equipe na captação de necessidades, identificação de prioridades e detecção de casos de risco para a intervenção dos outros profissionais (SILVA; DALMASO, 2002, p. 79), sua capacitação deve contemplar conhecimentos diversos em torno da questão do processo saúde- 
doença, ultrapassando a perspectiva puramente biomédica e incorporando outros saberes que o habilitem nesse processo de interação cotidiana com as famílias e no reconhecimento de suas necessidades (NUNES et al., 2002). Para isso, os princípios do SUS precisam ser enfatizados, compreendidos e incorporados na prática profissional dos ACS, não só para que eles atuem com autonomia profissional e segurança, promovendo o cuidado e o acolhimento, mas também para cumprirem com o seu papel na implantação deste sistema de saúde.

A consolidação do SUS requer a renovação permanente de iniciativas que visem a resgatar, assegurar e implementar os seus princípios a partir de práticas pedagógicas que permitam a reflexão crítica dos sujeitos envolvidos e o empoderamento - ampliação das possibilidades de controle, por um sujeito ou uma população, dos aspectos significativos relacionados à sua própria existência - para promover a libertação dos indivíduos e coletividades (COTTA et al., 2007). Neste sentido, o processo de capacitação dos profissionais de saúde, em especial do ACS, deve se basear na lógica do modelo da produção social da saúde, tendo como referência as necessidades de saúde das pessoas e das populaçôes, com o objetivo, por um lado, de transformar as práticas profissionais e a própria organização do trabalho, e por outro, de promover a articulação do saber científico com o saber popular, a partir da educação crítico-reflexiva e da metodologia problematizadora (BESEN et al., 2007; NORONHA et al., 2009).

Parafraseando Freire (2002), através da problematização e da análise dialética entre o contexto teórico e a realidade social em que se encontram, os educandos vão organizando uma forma cada vez mais crítica de pensar e poderão atuar cada vez mais seguramente no mundo, despertando a atitude dos que sabem que, para fazer o impossível, é preciso torná-lo possível. Portanto, quanto mais crítico um grupo humano, tanto mais democrático e permeável, em regra; tanto mais democrático quanto mais ligado às condições de sua circunstância e inserção no mundo.

Ademais, a "arte da alteridade", isto é, o deslocamento do "eu" em direção ao "outro", também deve ser incluída neste processo de capacitação e educação permanente para superação das práticas tradicionais de saúde, aliando as competências dos profissionais com as necessidades das diversas coletividades para se alcançar uma educação bem-sucedida no campo da saúde (COTTA et al., 2007, p. 283), e como conseqüência, promover o resgate do cuidado em saúde e a prática de suas diversas dimensões, tais como o acolhimento, a humanização, a compaixão, 
a resiliência, entre outras, o que certamente contribuirá com a resolubilidade das ações e serviços de saúde e com a efetiva implementação do SUS.

Embora a problemática apresentada seja bastante desafiadora, o Ministério da Saúde tem se preocupado e buscado, cada vez mais, estratégias de enfrentamento para as dificuldades que entravam a operacionalização e o aperfeiçoamento do SUS, dentre as quais merecem destaque a Política Nacional de Humanização e a Política Nacional de Educação Permanente em Saúde.

A Política Nacional de Humanização foi criada em 2003 e se apresenta como oferta metodológica, reconhecendo a força e a capacidade de criação dos sujeitos, assim como a possibilidade de construir ações e projetos comuns, diante da necessidade de reposicionar a organização dos serviços, as ofertas de cuidado e os processos de trabalho, valorizando, sobremaneira, as formas de relação entre os sujeitos. Para isso, a política adota como diretrizes o acolhimento, a inclusão, a ampliação da clínica, a gestão compartilhada, entre outros dispositivos que permitem operar a humanização na realidade concreta (BRASIL, 2004).

Do mesmo modo, a Política Nacional de Educação Permanente em Saúde ${ }^{4}$ surge como uma proposta de ação estratégica para transformar e qualificar as ações em saúde, a partir da reestruturação dos processos e das práticas pedagógicas na formação dos profissionais de saúde (BRASIL, 2009). Esta política desponta como resposta ao desafio imposto à Educação, diante da necessidade de se criar novos objetos de linguagem e avaliação (ALVES, 2003) e cumprindo com as tendências atuais da área, que apontam para a utilização de metodologias ativas de ensino-aprendizagem, visando a tornar o educando o protagonista do seu próprio processo de formação (SILVEIRA; DOHMS, 2006).

Utilizando instrumentos capazes de desencadear uma visão do todo e de incentivar a construção de redes de mudanças sociais que possibilitem a expansão da consciência individual e coletiva (SILVEIRA; DOHMS, 2006; MITRE et al., 2008), o enfoque ressaltado na proposta da Política Nacional de Educação Permanente em Saúde procura aproximar a educação da vida cotidiana, com o objetivo de transformar as situaçôes diárias em aprendizagem, por meio da análise reflexiva dos problemas da prática (BRASIL, 2009).

Como resultado, os efeitos destas opções têm permitido mudanças importantes no trabalho em saúde, recompondo a aliança ética de defesa da vida entre gestores, trabalhadores e usuários (BRASIL, 2004), principalmente em função da ênfase 
no processo de trabalho e da estratégia da problematização, que não se limita a determinadas categorias profissionais, mas a toda a equipe, incluindo médicos, enfermeiros, ACS, pessoal administrativo, professores, trabalhadores sociais e todas as variantes de atores que formam o grupo (BRASIL, 2009).

\section{Considerações finais}

Não há dúvidas de que o ACS possui um papel importante para a consolidação do SUS, não só por facilitar o acesso da população às ações e serviços de saúde, mas principalmente por ser o elo entre as equipes de saúde e a comunidade, fortalecendo as relaçôes, facilitando o potencial diagnóstico das situações de risco e atuando como agentes de organização da comunidade para a transformação de suas condiçôes de saúde. No entanto, a maioria dos trabalhos evidencia que sua formação profissional continua centrada no controle tecnológico da doença, fazendo com que ele reproduza a visão positivista, fragmentada e reducionista do modelo biomédico em sua prática, atuando, não raras vezes, como "polícia sanitária".

Romper com essa visão exige uma capacitação permanente, que inclua os princípios do SUS sob um enfoque problematizador, baseado na construção compartilhada do conhecimento e na experiência cotidiana desses profissionais - relato de suas práticas -, assim como na orientação do trabalho segundo a visão fenomenológica e dialética da saúde, visando a subsidiar e priorizar as ações de promoção da saúde, prevenção dos agravos e enfermidades e de transformação social.

Além disso, não se pode exigir do ACS o árduo e complexo papel de ser a “mola propulsora da consolidação do SUS". Na prática, este processo depende de um conjunto de fatores técnicos, políticos, sociais e o envolvimento de diferentes atores, incluindo os próprios ACS, que, sem dúvida, têm um papel fundamental, juntamente com os demais profissionais de saúde, técnicos e gestores, assim como os outros setores da sociedade (TOMAZ, 2002, p. 85-86).

Destarte, segundo Mendes (2005, p. 51):

muito diferente das propostas alternativas que vêm sendo apresentadas, quase todas, resultado de elaboraçóes tecnocráticas e acolhidas por grupos de interesse e apresentadas dentro da cultura nacional de planos mágicos, o SUS segue a melhor tradição de reformas democráticas, negociadas na sociedade. Portanto, o SUS é, a um tempo, um processo legal e legítimo e, também, um processo em marcha, portanto inacabado. 
Assim, a proposta da Política Nacional de Educação Permanente em Saúde surge como estratégia potencial para a concretização da reflexão ampliada sobre o processo saúde-doença-adoecimento e do seu papel no contexto do cuidado, o que poderá, por um lado suscitar a curiosidade e a necessidade de avançar no conhecimento, e, por outro, estimular o desenvolvimento da autonomia profissional e a capacidade crítica e reflexiva de análise pelos profissionais de saúde, em especial pelos ACS.

Para isso, os conteúdos a serem abordados devem ser explorados com base em perspectivas autênticas da prática, considerando sua consistência e funcionalidade para o enfrentamento de situações reais, de forma que a reconstrução de significados ultrapasse uma aprendizagem baseada simplesmente na reprodução teórica do conhecimento e se converta em uma aprendizagem que tenha como pressuposto a participação ativa do ACS e uma efetiva integração da teoria com a prática.

\section{Referências}

ALVES, R. Conversas com quem gosta de ensinar. 6. ed. São Paulo: Papirus, 2003.

BESEN, C.B.; NETTO, M.S.; DA ROS, M.A. et al. A Estratégia Saúde da Família como objeto de educação em saúde. Saúde e Sociedade, v. 16, n. 1, p. 57-68, jan-abr 2007.

BORDIEU, P. Razōes práticas: sobre a teoria da ação. Tradução: Mariza Corrêa. Campinas: Papirus, 6. ed., 2005. 224 p.

BORNSTEIN, V.J.; STOTZ, E.M. Concepções que integram a formação e o processo de trabalho dos agentes comunitário de saúde: uma revisão de literatura. Ciência \& Saúde Coletiva, v. 13, n. 1, p. 259-268, 2008.

BRASIL. Ministério da Saúde. Norma Operacional Básica do SUS (NOB- SUS 01/96). Gestão plena com responsabilidade pela saúde da população. Diário Oficial da União, 06 de novembro de 1996. Brasília, DF, 1996. Disponível em: <www.saude.gov.br>. Acesso em: 27 jun. 2008.

BRASIL. Ministério da Saúde. Portaria no. 1886/GM, de 18 de dezembro de 1997. Aprova as Normas e Diretrizes do Programa de Agentes Comunitários de Saúde. Brasília, DF, 1997. Disponível em: <www.saude.gov.br>. Acesso em: 07 mar. 2008.

BRASIL. Ministério da Saúde. Decreto no 3.189, de 4 de outubro de 1999. Fixa diretrizes para o exercício da atividade de Agente Comunitário de Saúde (ACS), e dá outras providências. Brasília, DF, 1999. Disponível em: <www.saude.gov.br>. Acesso em: 08 fev. 2008.

BRASIL. Ministério da Saúde. Secretaria Executiva. Programa Saúde da Família. Brasília: Ministério da Saúde, 2001. 36p. 
BRASIL. Ministério da Saúde. Lei no. 10.507, de 10 de julho de 2002. Cria a profissão de agente comunitário de saúde e dá outras providências. Brasília, DF, 2002. Disponível em: <www.saude.gov.br>. Acesso em: 08 fev. 2008.

BRASIL. Ministério da Saúde. Secretaria Executiva. Núcleo Técnico da Política Nacional de Humanização. HumanizaSUS: Política Nacional de Humanização: a humanização como eixo norteador das práticas de atenção e gestão em todas as instâncias do SUS. Brasília, 2004. Disponível em: <www.saude.gov.br>. Acesso em: 09 out. 2007.

BRASIL. Ministério da Saúde. Secretaria de Atenção à Saúde. Departamento de Atenção Básica. Política Nacional de Atenção Básica. 4. ed., Brasília: Ministério da Saúde, 2006. 68 p. Série E. Legislação de Saúde. Série Pactos pela Saúde 2006; v. 4.

BRASIL. Ministério da Saúde. Secretaria de Gestão do Trabalho e da Educação na Saúde. Departamento de Gestão da Educação em Saúde. Política Nacional de Educação Permanente em Saúde. Brasília: Ministério da Saúde, 2009. 64 p. (Série Pactos pela Saúde 2006, 9). Disponível em: <www.saude.gov.br>. Acesso em: 28 fev. 2010.

BRASIL. Ministério da Saúde. Departamento de Atenção Básica. Atenção Básica e Saúde da Familia: Histórico de Cobertura da Saúde da Família. Disponível em: <http://200.214.130.35/ dab/abnumeros.php\#mapas> Acesso em: 19 nov. 2010.

BUCHABQUI, J.A.; CAPP, E.; PETUCO, D.R.S. Convivendo com agentes de transformação: a interdisciplinaridade no processo de ensino/aprendizado em saúde. Revista Brasileira de Educação Médica, Rio de Janeiro, v. 30, n. 1, p. 32-38, jan.-abr. 2006.

BYDLOWSKI C.R.; WESTPHAL M.F.; PEREIRA I.M.T.B. Promoção da saúde: porque sim e porque ainda não? Saúde e Sociedade v. 13, n. 1, p. 14-24, jan.-abr. 2004.

CAMPOS, C.E.A. O desafio da integralidade segundo as perspectivas da vigilância da saúde e da saúde da família. Ciência \& Saúde Coletiva, v. 8, n. 2, p. 569-584, 2003.

CAPRA, F. A teia da vida: uma nova compreensão científica dos sistemas vivos. 6.ed. São. Paulo: Cultrix, 2001. 256p.

CAPRA, F. O ponto de mutação. Tradução: Álvaro Cabral; São Paulo: Cultrix, 2006. 447 p. COTTA, R.M.M.; AZEREDO, C.M.; SCHOTT, M. et al. Sobre o conhecimento e a consciência sanitária brasileira: o papel estratégico dos profissionais e usuários no sistema sanitário. Revista Médica Minas Gerais, v. 16, n. 1, p. 2-8, 2006.

COTTA, R.M.M.; GOMES, A.P.; MAIA, T.M. et al. Pobreza, injustiça e desigualdade social: repensando a formação de profissionais de saúde. Revista Brasileira de Educação Médica. Rio de Janeiro, v. 31, n. 3, p. 278-286, 2007.

DAL POZ, M.R. O agente comunitário: algumas reflexões. Interface: Comunicação, Saúde, Educação, v. 6, n. 10, p. 75-94, fev. 2002. 
DIAS, G.; FRANCESCHINI, S.C.C.; REIS, J.R. et al. A vida nos olhos e o coração nas mãos: concepções e representações femininas do processo saúde doença. História, Ciências, Saúde: Manguinhos, Rio de Janeiro, v. 14, n. 3, p. 779-800, 2007.

DUARTE, R.L.; SILVA, D.S.JR.; CARDOSO, S.H. Construindo um programa de educação com agentes comunitários de saúde. Interface: Comunicação, Saúde, Educação. Botucatu, v. 11, n. 23, p. 439-47, set.-dez. 2007.

FALCÓN, G.S.; ERDMANN, A.L.; Meirelles, B.H.S. A complexidade na educação dos profissionais para o cuidado em saúde. Texto Contexto Enfermagem. Florianópolis, v. 15, n. 2, p. 343-51, abr-jun. 2006.

FERRAZ, L.; AERTS, D.R.G.C. O cotidiano do agente comunitário de saúde no PSF em Porto Alegre. Ciência \& Saúde Coletiva, v. 10, n. 2, p. 347-355, 2005.

FRANCO, T.; MERHY, E. PSF: Contradições e desafios. Conferência Nacional de Saúde On-Line. Belo Horizonte/Campinas, 1999. Disponível em: <http://www.datasus.gov.br/ cns/temas/tribuna/PsfTito.htm>. Acesso em: 10 abr. 2008.

FREIRE, P. Pedagogia do oprimido. 28. ed. Rio de Janeiro: Paz e Terra, 1987. 220p.

FREIRE, P. Ação cultural para a liberdade e outros escritos. 10. ed. São Paulo: Paz e Terra, 2002. 176p.

KLUTHCOVSKY, A.C.G. C. et al. Avaliação da qualidade de vida geral de agentes comunitários de saúde: a contribuição relativa das variáveis sociodemográficas e dos domínios da qualidade de vida. Revista de Psiquiatria do Rio Grande do Sul, v. 29, n. 2, p. 176-183, 2007.

LEFEVRE, F.; LEFEVRE, A.C. Saúde como negação da negação: uma perspectiva dialética. Physis: revista de Saúde Coletiva. Rio de Janeiro, v. 17, n. 1, p. 15-28, 2007.

LEVY, F.M.; MATOS, P.E.S.; TOMITA, N.E. Programa de agentes comunitários de saúde: a percepção de usuários e trabalhadores de saúde. Cadernos de Saúde Pública. Rio de Janeiro, v. 20, n. 1, p. 197-203, jan.-fev. 2004.

MARCONDES, W.B. A convergência de referências na promoção da saúde. Saúde e Sociedade, v. 13, n. 1, p. 5-13, jan.-abr. 2004.

MENDES, E.V. SUS: um processo social em construção. Disponível em: <http://www. opas.org.br/rh/publicacoes/textos_apoio/ACF9371.pdf> Acesso em: 28 jun. 2005.

MENDES, E.V. Uma agenda para a saúde. São Paulo: Hucitec, 2006. 300 p.

MINAYO, M.C.S. O desafio do conhecimento: pesquisa qualitativa em saúde. 10. ed. São Paulo: Hucitec, 2007. 406 p.

MITRE, S.M.; SIQUEIRA-BATISTA, R.; GIRARDI-DE-MENDONÇA, J.M. et al. Metodologias ativas de ensino-aprendizagem na formação dos profissionais de saúde: debates atuais. Rev. de Ciência \& Saúde Coletiva, v. 13, supl. 2, p. 2.133-2.144, dez., 2008. 
NOGUEIRA, R.P.; SILVA, F.B.; RAMOS, Z.V.O. A vinculação institucional de um traba-

lhador sui generis: o agente comunitário de saúde. Rio de Janeiro: Ipea, 2000. 33p. (Textos para Discussão, 735).

NORONHA, M.G.R.C.S.; CARDOSO, P.S.; MORAES, T.N.P. et al. Resiliência: nova perspectiva na Promoção da Saúde da Família? Ciência \& Saúde Coletiva, v. 14, n. 2, p. 497-506, 2009.

NUNES, M.O.; TRAD, L.B.; ALMEIDA, B.A. et al. O agente comunitário de saúde: construção da identidade desse personagem híbrido e polifônico. Cadernos de Saúde Pública. Rio de Janeiro, v. 18, n. 6, p. 1639-1646, nov.-dez. 2002.

PAIM, J.S. Saúde da Família: espaço de reflexão e de contra-hegemonia. Interface - Comunicação, Saúde, Educação v.5, n.9, p.143-146, 2001.

PEDROSA, J.I.; TELES, J.B.M. Consenso e diferenças em equipes do Programa Saúde da Família. Revista Saúde Pública, v. 35, n. 3, p. 303-11, 2001.

CAMPOS, G.W. O SUS é melhor que o Brasil. Radis, Rio de Janeiro, v. 62, p. 16-17, out. 2007. REGO, S.; GOMES, A.P.; SIQUEIRA-BATISTA, R. Humano demasiado humano: bioética e humanização como temas transversais na educação médica. Cadernos $A B E M$, v. 3, p. 24-33, out. 2007.

RICHARDSON, R.J. et al. Pesquisa Social: métodos e técnicas. 3. ed. São Paulo: Atlas; 1999. $335 \mathrm{p}$.

RIOS, E.R.G.; FRANCHI, K.M.B.; SILVA, R.M. et al. Senso comum, ciência e filosofia: elo dos saberes necessários à promoção da saúde. Ciência \& Saúde Coletiva. Rio de Janeiro, v. 12, n. 2, p. 501-509, 2007.

ROSA, A.S.; CAVICCHIOLI, M.G.S.; BRÊTAS, A.C.P. O significado que o agente comunitário de saúde atribui ao seu trabalho no processo de construção do Sistema Único de Saúde no Brasil. Acta Paulista Enfermagem, v. 17, n. 3, p. 255-261, jul.-set. 2004.

SANTOS, J.L.F.; WESTPHAL, M.F. Práticas emergentes de um novo paradigma de saúde: o papel da universidade. Estudos Avançados, v. 13, n. 35, p. 71-88, 1999.

SCHERER, M.D.A.; MARINO, S.R.A.; RAMOS, F.R.S. Rupturas e resoluções no modelo de atenção à saúde: reflexôes sobre a estratégia saúde da família com base nas categorias kuhnianas. Interface: Comunicação, Saúde, Educação, v. 9, n. 16, p. 53-66, 2005.

SILVA, J.A.; DALMASO, A.S.W. Agente comunitário de saúde: o ser, o saber, o fazer. Rio de Janeiro: Fiocruz, 2002, 240p.

SILVA, J.A.; DALMASO, A.S.W. O agente comunitário de saúde e suas atribuições: os desafios para os processos de formação de recursos humanos em saúde. Interface: Comunicação, Saúde, Educação, v. 6, n. 10, p. 75-96, fev. 2002. 
SILVEIRA, R.P.; DOHMS, M.C. A Medicina de Família e Comunidade e o ensino de graduação em medicina. Metodologias ativas de Ensino/Aprendizagem. Rev. Brasileira de Medicina de Família e Comunidade, Supl. 1, p. 21-25, 2006.

STOTZ, E.N.; ARAUJO, J.W.G.A. Promoção da saúde e cultura política: a reconstrução do consenso. Saúde e Sociedade, v. 13, n. 2, p. 5-19, maio-ago. 2004.

TESSER, C.D. Medicalização social (II): limites biomédicos e propostas para a clínica na atenção básica. Interface - Comunicação, Saúde, Educação, v. 10, n. 20, p. 347-62, jul.-dez. 2006.

TOMAZ, J.B.C. O agente comunitário de saúde não deve ser um "super-herói”. Interface: Comunicação, Saúde, Educação, v. 6, n. 10, p. 75-94, fev. 2002.

TRIVIÑOS, A.N.S. Introdução à pesquisa em ciências sociais: a pesquisa qualitativa em educação. São Paulo: Atlas, 1987. 175 p.

VASCONCELOS, E.M. Educação popular e a atenção à saúde da família. 3. ed. São Paulo: Hucitec, 2006. 336 p.

ZANCHETTA, M.S. et al. Educação, crescimento e fortalecimento profissional do agente comunitário de saúde: estudo etnográfico. Online Brazilian Journal of Nursing, v. 4, n. 3, 2005. Disponível em: <http://www.uff.br/nepae/objnursing.htm>. Acesso em: 04 dez. 2007.

\section{Notas}

${ }^{1}$ Este artigo é parte da dissertação Programa Saúde da Família - da assistência ao cuidado: avaliação da implementação da Atenção Primária à Saúde", defendida por Karine de Oliveira Gomes no Programa de Pós-Graduação em Ciência da Nutrição do Departamento de Nutrição e Saúde da Universidade Federal de Viçosa-MG, orientada pela Prof ${ }^{a}$. Dr ${ }^{a}$. Rosângela Minardi Mitre Cotta.

${ }^{2}$ Estudo financiado pela FAPEMIG - Processo no EDT - 3332/06. Edital: 005/2006 - Programa de Pesquisa para o SUS - Sistema Único de Saúde de Minas.

${ }^{3}$ Em 2003, foi criada a Política Nacional de Humanização (HumanizaSUS): Política Nacional de Humanização: a humanização como eixo norteador das práticas de atenção e gestão em todas as instâncias do Sistema Único de Saúde - SUS), como estratégia de valorização da capacidade de criar e avançar rumo à superação das dificuldades e carências do sistema. Os principais objetivos desta política são destacados em seus Princípios Norteadores:

1. Valorização da dimensão subjetiva e social em todas as práticas de atenção e gestão, fortalecendo/ estimulando processos integradores e promotores de compromissos/responsabilização;

2. Estímulo a processos comprometidos com a produção de saúde e de sujeitos;

3. Fortalecimento do trabalho em equipe multiprofissional, estimulando a transdisciplinaridade e a grupalidade;

4. Atuação em rede com alta conectividade, de modo cooperativo e solidário, em conformidade com as diretrizes do SUS;

5. Utilização da informação, da comunicação, da educação permanente e dos espaços da gestão na construção de autonomia e protagonismo de sujeitos e coletivos. [grifo nosso] 
${ }^{4}$ A Política Nacional de Educação Permanente foi instituída pela Portaria GM/MS no 198 , de 13 de fevereiro de 2004, e alterada pela Portaria GM/MS no 1.996, de 20 de agosto de 2007. Esta política exige um trabalho intersetorial capaz de articular o desenvolvimento individual e institucional, açôes e serviços, gestão setorial, atenção à saúde e controle social, através de açôes baseadas nas seguintes diretrizes:

1. Destinam-se a públicos multiprofissionais;

2. Possuem enfoque nos problemas cotidianos das práticas das equipes de saúde;

3. Inserem-se de forma institucionalizada no processo de trabalho, gerando compromissos entre os trabalhadores, os gestores, as instituições de ensino e os usuários para o desenvolvimento institucional e individual;

4. Objetivam as transformações das práticas técnicas e sociais;

5. Utilização de pedagogias centradas na resolução de problemas, geralmente por meio de supervisão dialogada, oficinas de trabalho, realizadas preferencialmente, no próprio ambiente de trabalho;

6. São contínuas dentro de um projeto de consolidação e desenvolvimento do SUS. 


\section{The Community Health Agent and the consolidation of the Unified Health System: contemporary reflections}

The community health agents (ACS) are key players in the implementation of policies related to the reorientation of health model, based on primary care. This study presents a literature review, led to critical analysis on the contribution of this work for the consolidation of the Unified Health System (SUS). Whereas the conception of health-disease process gives meaning to the practice and actions of health professionals, first we discussed the evolution of the paradigms of health and the influence of currents of thought in this process, presenting the main differences between the paradigm and Flexnerian paradigm of social production of health. In this context, the SUS emerged as a new health system, with principles and guidelines that make up the Family Health Program a revolutionary strategy which presents answers to the unsolved problems by the hegemonic health system, based on the paradigm dominant so far. So, focusing on care, primary care, health surveillance practices and multi-professional teamwork, professional training to address the health-disease process with a focus on family health poses a challenge to the success of the proposed public health model. Thus, critical reflection on the role of the ACS points to conflicts between the theoretical model and professional practice, highlighting the need for ongoing training, critical and reflective and based on questionable methodology, such as augmentation strategy for the effective change in the health model in the context of the praxis of the Family Health Program.

Key words: Community Health Agent; Single Health System; Family Health Program; Professional Education; Problem Based Learning. 